\title{
Structural monitoring of Lezíria Bridge since its construction
}

\author{
H. Sousa \& J. Figueiras \\ LABEST, Faculty of Engineering, University of Porto, Porto, Portugal
}

J. Bento

BRISA - Auto-Estradas de Portugal S.A., Lisboa, Portugal

\begin{abstract}
Currently, automatic monitoring systems are increasingly used in the civil engineering structures especially in bridges with a high socioeconomic impact. In the last decades, the technology evolution that the world has being subjected allow, nowadays, the implementation of monitoring systems capable of observe the structural behavior in a programmable, remote and real-time manner. The databases originated by the sensors records are valuable information to understand better the real behavior of the monitored structures as well to improve the numerical models used in the analysis and prediction. This work presents the Lezíria Bridge case, equipped with an integrated and automatic monitoring system. This system allows the observation of the structural behavior and the materials durability. A presentation and discussion of a set of results obtained since the bridge construction is performed. The principal considerations refer to: (i) environmental effects - temperature and humidity; (ii) rheological effects of concrete - creep and shrinkage; (iii) events related with the bridge construction, long-term behavior and short-term behavior correlated to the bridge traffic. A final discussion is presented which is focused the usefulness of the information obtained by the monitoring system for the assessment and surveillance of the structure.
\end{abstract}

\section{INTRODUCTION}

In the last century, bridge infrastructures faced significant improvements and a speedup in the construction processes with the affirmation of concrete and steel materials that allowed new forms and higher strengths. However, neither concrete nor steel structures are maintenance-free, and deteriorations problems such as fatigue and corrosion of steel structures and frost damage, alkaline silica response and carbonation of concrete, in the case of the concrete structures (Arenas et al. 1998), are a reality.

At present, and certainly more in the future, climatic changes are being gradually taken seriously. Péter Lenkei refers in (Jordet et al. 2007) the impact of those climatic changes in structural engineering, namely temperature, wind and precipitation changes. It is referred the impact of those changes in the safety and maintenance of civil structures, like impact of higher wind speed, different wind profiles, deterioration of structures surfaces, and damage to the water tightness of different elements.

Bridges are also exposed to a traffic increase, measured both in the number of vehicles as well as in their weight. For the safety of bridges this is a critical aspect, since many of them are carrying average loads higher than predicted during their design.
In this context, bridge maintenance is a critical aspect where the health monitoring systems has an important contribution as an active alarm system. The use of those systems has increased steadily, as a way to give information about bridges' performance over the past few years (Karoumi 2004). In some countries, there were real cases of bridges collapse that have hurried the use of the monitoring systems (Barcina et al. 1997, Ridruego 2006).

With new bridge designs in place and the materials evolution meanwhile achieved, the long-term prediction of the bridges behavior became a complex task. The monitoring systems applied permanently are generating valuable knowledge about the real behavior of bridge structures, contributing to evaluate design assumptions, finite element models, and safety coefficients. Relevant contributions in this domain have been recognized to the information collected by those systems (Buonomo et al. 2004, Curran et al. 1999, Ducret et al. 1999, Froli et al. 1996, García et al. 1998, Luengo et al. 2000, Tang et al. 2002, Tomita et al. 1999).

\section{RESEARCH SIGNIFICANCE}

In this work it is intended to present the long-term monitoring system of Lezíria Bridge by a discussion 
of a set of results obtained since the construction. The gathered results provide valuable information for further study and for the understanding of the real behavior of the structure. Through an adequate data treatment and processing to a higher level of information abstraction, it is intended to demonstrate the utility of this type of systems to help on the assessment and surveillance of the structure.

\section{LEZÍRIA BRIDGE}

\subsection{The structure}

The Lezíria Bridge, built between 2005 and 2007, is inserted in the A10 - Highway Bucelas / Carregado (A1) / IC3 (A13). With a total length of $39.9 \mathrm{~km}$, this highway is an outside bound to the Lisbon Metropolitan Area, the Portuguese capital. It benefits those who wish to go to Alentejo / Algarve (A2 highway) and Spain (A6 highway), without crossing the capital. Besides that this new bridge is improving the accessibility between Vila Franca de Xira e the Samora Correia/Benavente municipalities leading to a considerable traffic relief in the EN10 and EN118 national roads (Oliveira 2006).

The $11,670 \mathrm{~m}$ total length of the Lezíria Bridge are materialized by three substructures: (i) the north approach viaduct with $1,700 \mathrm{~m}$ of length; (ii) the main bridge substructure, crossing the Tagus river, with a total length of $970 \mathrm{~m}$; (iii) and the largest substructure, the south approach viaduct, with a total length of $9,160 \mathrm{~m}$.

From the three substructures, the north approach viaduct provides the connection to the A 1 highway. The north viaduct structure has three elementary girder viaducts (V1N to V3N), with current spans of $33 \mathrm{~m}$ of length, except at the crossing with a railway line in which the largest span has $65 \mathrm{~m}$ and is partially formed by a box girder. The bridge deck is supported by piers-pile with length that can reach $40 \mathrm{~m}$ deep. The railway line that crosses the north viaduct and the existence of an electric power plant and a neighbor substation were constraints considered in the project (Fig. 1-a).

The bridge structure is formed by 8 spans and 7 piers supported by pile caps over the river bed. The spans length is $130 \mathrm{~m}$ except the end spans, with $95 \mathrm{~m}$, and two of the mid spans that differ in $5 \mathrm{~m}$ due to a change in a pier implementation leading to spans with $125 \mathrm{~m}$ and $135 \mathrm{~m}$ of length. The bridge deck is materialized by a box girder of variable inertia with about $10.0 \mathrm{~m}$ of with and heights varying between $4.0 \mathrm{~m}$ and $8.0 \mathrm{~m}$. The box girder core construction was made by segmental construction using a movable scaffolding while the side consoles were subsequently built sustained by a different movable scaffolding and metallic struts fixed in the bottom slab of the box girder. The concrete piers are formed by four walls with constant thickness and variable width and are supported by pile caps ( 8 piles in general and 10 in the two pile caps bounding the navigation channel) (Fig. 1-b).

The south approach viaduct has 22 elementary viaducts (V1S to V22S) with extensions ranging from $250 \mathrm{~m}$ to $530 \mathrm{~m}$. It has a span length of $36 \mathrm{~m}$, with exceptions due to the existence of irrigation canals and dikes in the Lezíria fields. The deck floor is supported by precast beams (executed in the construction site, where a precast industrial unit was specifically built), and monolithically linked to the piers. Supported by the precast beams the top layer of the deck floor is formed by precast slabs, also serving as formwork to the in situ concreting. Like the north viaduct the bridge deck is supported on piers-pile with lengths varying from $35 \mathrm{~m}$ to $60 \mathrm{~m}$ deep, given the need for crossing alluviums with variable constitution (Fig. 1-c).
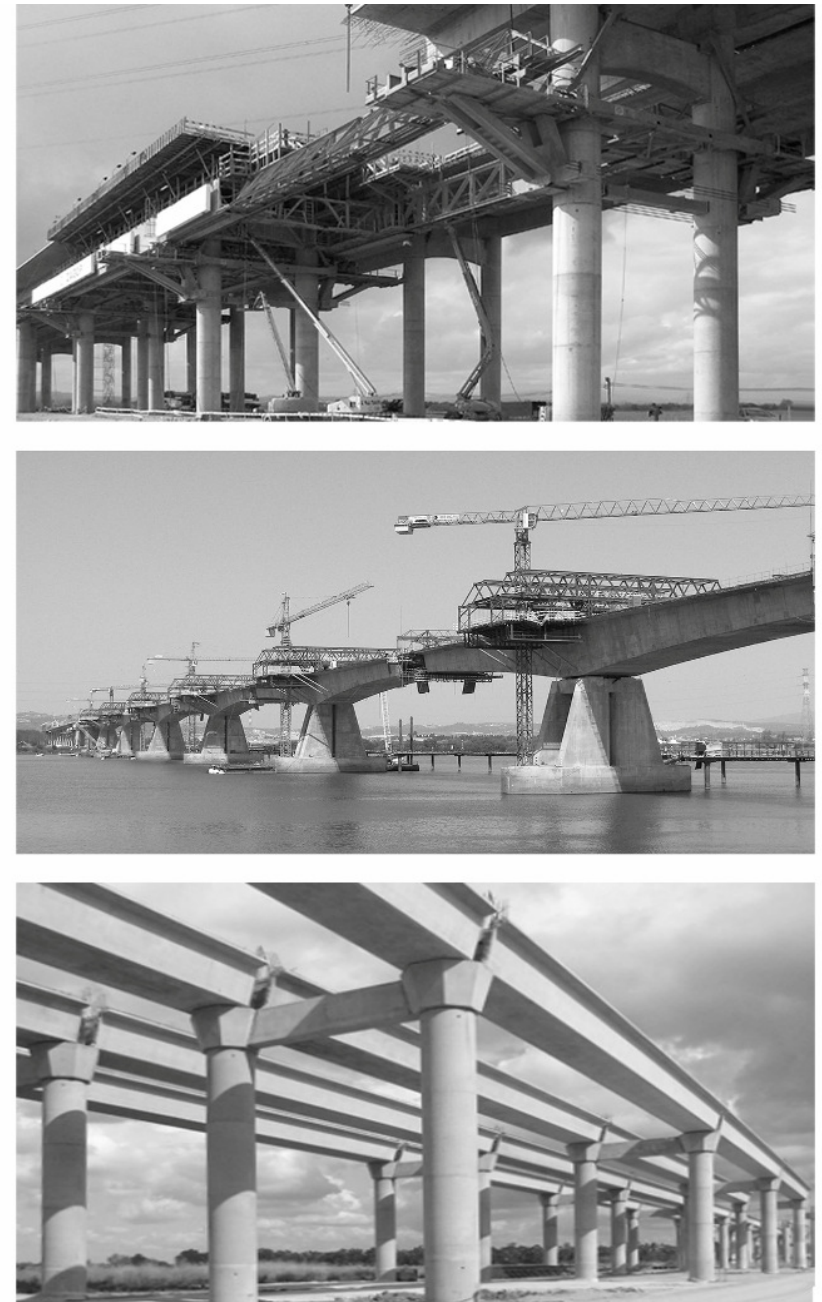

Figure 1. Lezíria Bridge - north viaduct (top), main bridge (middle) and south viaduct (bottom).

\subsection{The monitoring system}

The Lezíria Bridge is equipped with an integrated monitoring system guided for the management and surveillance of the structure (Figueiras, 2007). Several cross sections are instrumented with embedded 
and external sensors distributed along the bridge length, which cross the three sub-structures (viaducts and main bridge). The installed sensors measure a set of quantities, since static, durability and dynamic parameters. The sensors and acquisition systems are based in electrical and optical technologies. Figure 2 illustrates the sensorial component with reference to the measured parameters, the project symbols as well the adopted abbreviations, and the types of the acquisition systems adopted to interrogate the sensors signal. Accordingly with the symbology adopted, Table 1 resumes the instrumented zones of the bridge.

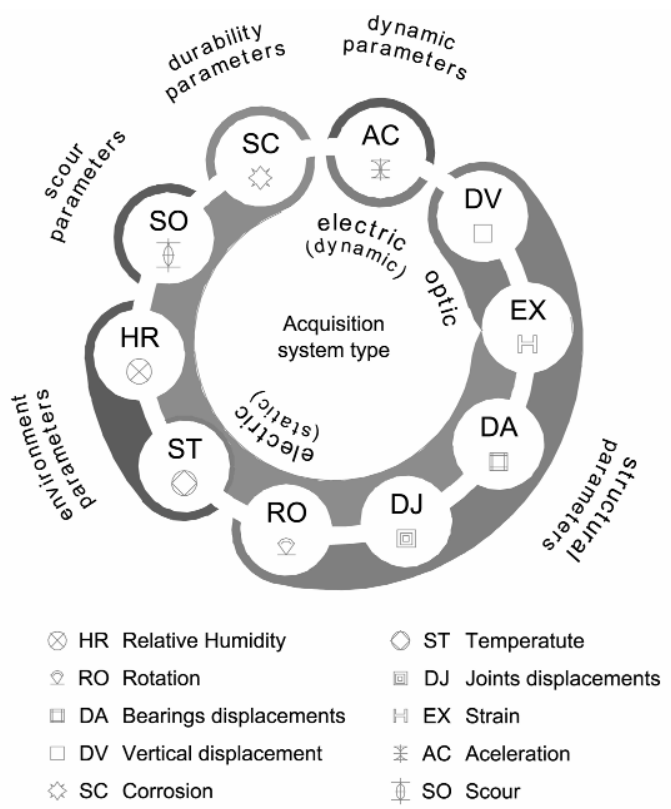

Figure 2. Constituents of sensorial component.

Table 1. Location of measured parameters.

\begin{tabular}{|c|c|c|c|c|c|}
\hline \multirow[t]{2}{*}{ Parameter } & \multicolumn{5}{|c|}{ Instrumented zones } \\
\hline & Soil & Piles & Pillars & Bearings & Deck \\
\hline $\mathrm{EX}$ & & $\checkmark$ & $\checkmark$ & & $\checkmark$ \\
\hline DJ, DA & & & & $\checkmark$ & \\
\hline RO & & & & & $\checkmark$ \\
\hline ST & & $\checkmark$ & $\checkmark$ & & $\checkmark$ \\
\hline $\mathrm{RH}$ & & & & & $\checkmark$ \\
\hline SO & & & $\checkmark$ & & \\
\hline $\mathrm{SC}$ & & & $\checkmark$ & & $\checkmark$ \\
\hline $\mathrm{AC}$ & $\checkmark$ & & $\checkmark$ & & $\checkmark$ \\
\hline DV & & & & & $\checkmark$ \\
\hline
\end{tabular}

\section{MONITORING RESULTS DATABASE}

Although in partial mode, the monitoring system started its operation during construction, mainly with the installation of the sensors embedded in concrete. Important construction events were followed by the monitoring system and measurements were stored in a valuable database related to this period of the bridge life.

Upon bridge completion, the monitoring system entered in full operation mode, although some adjustments have been made in the system in the first months due to the sensitivity of the measurements to various noise sources. Since then, the database has been growing continuously at a rhythm of 1 million records per year, approximately, with a set of interesting short and long term events.

\subsection{Environmental conditions}

The long-term observation of a bridge behavior is strongly dependent on the environmental factors, namely temperature and humidity. These two factors have an important influence, namely in the expansion/contraction of the structural materials with implications in the bending behavior of pillars, bearings performance, and the health of the expansion joints. Also the corrosion in the reinforcement is a critical aspect, where the knowledge of the evolution of these parameters provides valuable information. Since the end of construction, this environmental parameters were measured and a statistical study was performed based in the almost three years of observation with reading samplings taken every hour. Figure 3 presents a histogram with the measured exterior temperature in the main bridge, as well a normal distribution fitting. Figure 4 presents the same procedure, but for the relative humidity measured in the south viaduct V14S.

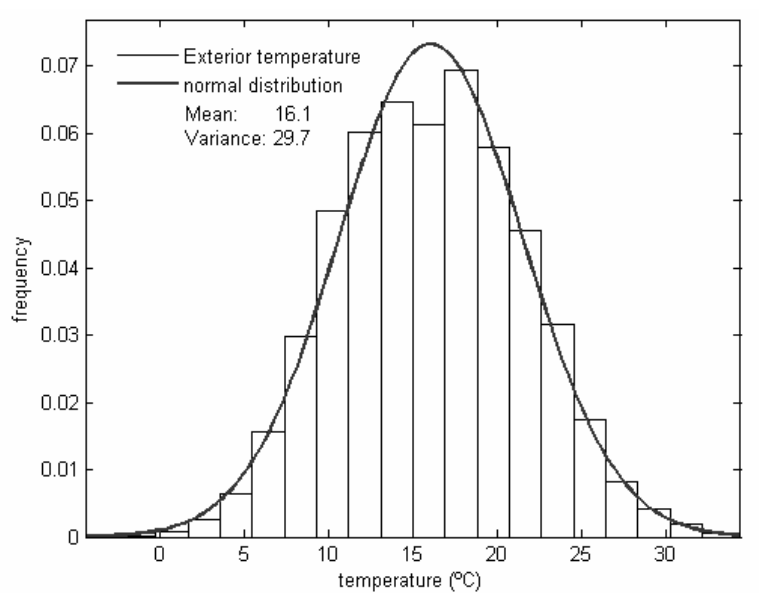

Figure 3. Exterior temperature distribution in the main bridge.

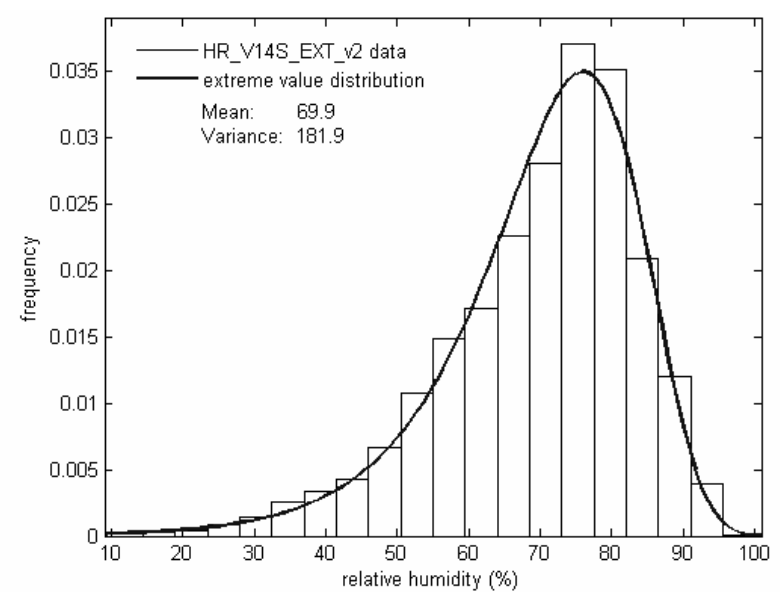

Figure 4. Exterior Relative Humidity distribution in V14S south viaduct. 
Table 2 resumes the same information for all the monitored zones of the Lezíria Bridge. The number of measurements for each one ranges between 11000 and 17500. A normal distribution was used to fit the temperature measurements and the extreme value distribution for the relative humidity, due to the fact that this parameter has a finite domain $[0,1]$.

Table 2. Statistical data of the temperature and relative humidity measured in Lezíria Bridge.

\begin{tabular}{|c|c|c|c|c|}
\hline \multirow[t]{2}{*}{ Bridge zone } & \multicolumn{2}{|c|}{ Temperature $\left({ }^{\circ} \mathrm{C}\right)$} & \multicolumn{2}{|c|}{ Relative humidity (\%) } \\
\hline & $\mu$ & $\sigma^{2}$ & $\mu$ & $\sigma^{2}$ \\
\hline \multicolumn{5}{|l|}{ North viaduct } \\
\hline Interior* & 16.8 & 32.6 & - & - \\
\hline Exterior & 15.3 & 34.4 & - & - \\
\hline \multicolumn{5}{|l|}{ Main bridge } \\
\hline Interior* & 18.8 & 28.9 & 51.8 & 97.8 \\
\hline Exterior & 16.1 & 29.7 & 64.0 & 123.2 \\
\hline \multicolumn{5}{|l|}{ South viaduct } \\
\hline Interior (V1S)* & 13.1 & 25.0 & 68.4 & 138.2 \\
\hline Exterior (V1S) & 11.5 & 26.3 & 69.3 & 162.0 \\
\hline Interior (V14S)* & * 18.6 & 29.1 & 90.3 & 19.9 \\
\hline Exterior (V14S) & 16.2 & 30.6 & 69.9 & 181.9 \\
\hline
\end{tabular}

* Inside the box girder deck.

Some considerations can be made from the presented results: (i) Compared with the exterior environment, the temperature inside the box girder of the deck is always greater in a range of $1.5^{\circ} \mathrm{C}$ to $2.7^{\circ} \mathrm{C}$; (ii) the mean value of all the measured temperatures is bellow $20^{\circ} \mathrm{C}$; (iii) the relative humidity of the exterior environment is more uniform, rounding the $70 \%$; (iv) inside the bridge deck, the relative humidity ranges from $52 \%$ inside the main bridge and $90 \%$ inside the south viaduct deck. Globally, the Lezíria bridge is exposed to a mild environment with significant relative humidity.

\subsection{Shrinkage and creep of concrete}

The experimental knowledge of the time dependent effects of concrete, namely shrinkage and creep, is crucial for an accurate interpretation of the real behavior of structures. In the Lezíria Bridge, a set of concrete prisms of dimensions $15 \times 15 \times 55 \mathrm{~cm}^{3}$ were provided with the propose of measure those time dependent effects. The prisms' pouring was always performed when an instrumented zone of the bridge was constructed. The environmental conditions of these prisms were the same of the respective constructed zone of the bridge, in order to have representative measurements of each phenomenon.

The obtained measurements were compared with theoretical models, namely the models of Eurocode 2 - EC2 (Beeby 2005). In the case of shrinkage, the instant that the drying shrinkage phenomenon starts, $t_{s}$, was fixed twenty four hours after the prisms pouring. For that reason, the autogenous shrinkage was neglected, and it is assumed that the total shrinkage is approximately equal to the drying shrinkage - $\varepsilon_{\mathrm{cs}}(\mathrm{t}) \cong \varepsilon_{\mathrm{cd}}(\mathrm{t})$. The creep prisms were pressured 145 hours (six days) after in the case of the north viaduct and 63 hours after in the case of the main bridge. In both cases, the prisms pressure operations matched with the prestressing of the instrumented zones of the bridge, in order to get an effective measure of the real creep evolution in the structure. Equation 1 and 2 present the multiplicative models of EC2 for drying shrinkage and creep respectively.

$$
\begin{aligned}
& \varepsilon_{c s}(t) \cong \varepsilon_{c d}(t)=\beta_{d s}\left(t-t_{s}\right) \cdot \varepsilon_{c d, \infty} \\
& \varepsilon_{c c}\left(t-t_{0}\right)=\varphi\left(t-t_{0}\right) \cdot \varepsilon_{c i}\left(t_{0}\right)
\end{aligned}
$$

The environmental conditions previously presented and the effective properties of the concrete were considered for parameters models definition. It must be highlighted that the authors had access to the concrete properties obtained from tests performed by the bridge constructor, which is part of the quality plan during the construction (TACE 2007). Figure 5 presents the experimental data collected from prisms placed inside the box girder of the main bridge, as well as EC2 model and EC2 model adjusted. The model adjustment was performed by a minimization problem between the measurements and the model, by considering some model parameters and additional parameters not deterministic, to allow the adjustment (Sousa et al. 2006). Table 3 and 4 resumes all the results obtained, with indication of a normalized error (in brackets) committed by each prediction. This normalized error is the standard deviation between the measurement and the models.

Table 3. Concrete shrinkage until 28 Oct 2009.

\begin{tabular}{lcclc}
\hline Bridge zone & age $*^{\mathrm{a}}$ & Prisms & EC2 & EC2 adjusted \\
\cline { 2 - 5 } & (days) & $\mu \varepsilon$ & $\mu \varepsilon$ & $\mu \varepsilon$ \\
\hline North viaduct & & & & \\
$\quad$ Exterior 1 & 1181 & -261 & $-399(149)$ & $-235(20)$ \\
$\quad$ Exterior 2 & 958 & -282 & $-401(126)$ & $-268(13)$ \\
Main bridge & & & & \\
Interior 1*b & 1022 & -366 & $-470(117)$ & $-347(11)$ \\
Interior 2*b & 1022 & -377 & $-477(114)$ & $-353(13)$ \\
Exterior 1 & 997 & -452 & $-390(43)$ & $-430(13)$ \\
Exterior 2 & 997 & -350 & $-395(56)$ & $-329(15)$ \\
South viaduct (precast beams) & & \\
Interior (V1S)*b 1022 & -357 & $-304(46)$ & $-364(12)$ \\
Exterior (V1S) & 1022 & -171 & $-304(127)$ & $-182(12)$ \\
Interior (V14S)*b 1174 & -79 & $-151(94)$ & $-51(18)$ \\
Exterior (V14S) & 1174 & -249 & $-367(146)$ & $-212(31)$ \\
South viaduct (deck floor) & & & \\
Interior (V1S)*b & 990 & -334 & $-368(36)$ & $-337(11)$ \\
Exterior (V1S) & 990 & -190 & $-368(173)$ & $-200(15)$ \\
Interior (V14S)*b 1097 & -140 & $-145(30)$ & $-127(8)$ \\
Exterior (V14S) & 1097 & -273 & $-352(117)$ & $-251(15)$ \\
\hline
\end{tabular}

\footnotetext{
$*^{\mathrm{a}}$ age counting from $\mathrm{t}_{\mathrm{s}}$.

${ }^{\text {b }}$ Inside the box girder deck.
} 
Table 4. Concrete creep until 28 Oct 2009.

\begin{tabular}{lcccc}
\hline Bridge zone & age $^{*^{\mathrm{a}}}$ & Prisms & EC2 & EC2 adjusted \\
\cline { 2 - 5 } & (days) & $\mu \varepsilon$ & $\mu \varepsilon$ & $\mu \varepsilon$ \\
\hline $\begin{array}{l}\text { North viaduct } \\
\quad \text { Exterior 1 }\end{array}$ & 1175 & -301 & $-593(271)$ & $-282(13)$ \\
Main bridge & & & & \\
$\quad$ Interior 1* & 1021 & -743 & $-754(62)$ & $-761(23)$ \\
$\quad$ Exterior 1 & 1021 & -525 & $-660(116)$ & $-520(23)$ \\
\hline
\end{tabular}

$*^{\mathrm{a}}$ age counting from $\mathrm{t}_{0}$ (instant of prisms pressuring).

$*^{\mathrm{b}}$ Inside the box girder deck.

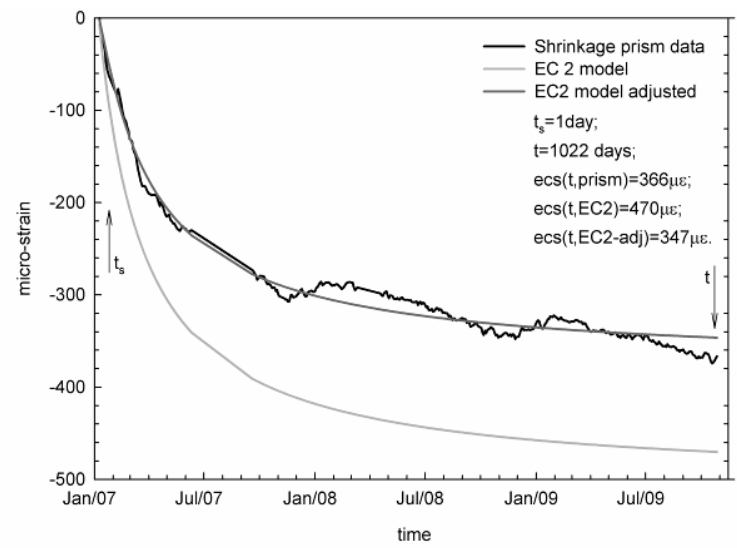

Figure 5. Concrete shrinkage measurements from prisms inside the box girder of the main bridge.

In general the EC2 models predict more shrinkage and creep deformations than those measured experimental. This fact leads to believe that the bridge pillars are under less bending efforts due to the time dependent effects, as well as the expansion joints are less open than the predicted. The EC2 models adjustment to the experimental data is useful information to a more accurate FEM models prediction.

\subsection{Construction monitoring - The north viaduct}

The north viaduct deck was built by a "beamlaunching" method. This construction method basically consists in the repetition of a sequence of four main steps: (i) "beam-launching" positioning between two consecutive pillars that bounds the span to build; (ii) construction of the deck span; (iii) deck prestressing; (iv) "launching beam" step forward to the next adjacent span to be build. Fig. 6 and Table 5 illustrate the construction steps related with the deck spans $\mathrm{P} 2 \mathrm{P} 3$ and $\mathrm{P} 3 \mathrm{P} 4$ of the north viaduct V2N. In that zone of the $\mathrm{V} 2 \mathrm{~N}$ viaduct, four sections were instrumented: (i) one pillar section near to the viaduct deck (pillar P1); (ii) three deck sections, with two located at mid span (span P1P2 and span P2P3) and one near to a pillar (pillar P2). To observe the axial and bending behavior of the instrumented sections, pairs of vibrating wire strain gauges were placed near to the coating concrete. Temperature sensors were also embedded.

Relevant considerations can be made. The most highlighted occurs with the application of a bending moment plus an axial force in the $\mathrm{P} 2 \mathrm{P} 3$ section due to the span prestressing (phase 1). The bottom strain gauges (EX-1 and EX-2) registered a variation approximately of $-300 \mu \varepsilon$. It's also possible to identify the structural effect of the construction events 2,3 and 4 , where the strain gauges exhibit a slight signal offset.

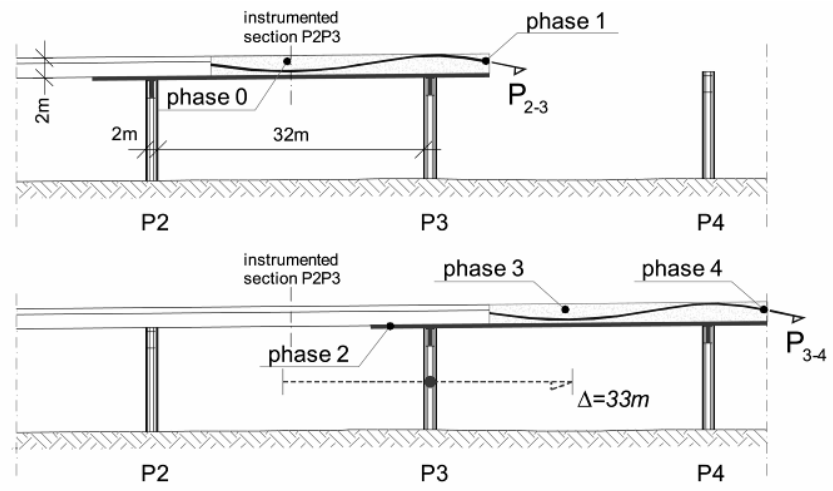

Figure 6. Deck construction by the "launching beam" method of the spans $\mathrm{P} 2 \mathrm{P} 3$ and $\mathrm{P} 3 \mathrm{P} 4$ of the $\mathrm{V} 2 \mathrm{~N}$ north viaduct.

Table 5. Principal construction events of the deck spans P2P3 and $\mathrm{P} 3 \mathrm{P} 4$.

\begin{tabular}{lll}
\hline Phase & \multicolumn{1}{c}{ date } & event description \\
\hline 0 & 03 Ago 2006 & Concreting of the V2N-P2P3 span \\
1 & 07 Ago 2006 & Prestressing of the V2N-P2P3 span \\
2 & 07 Ago 2006 & Running beam advance \\
3 & 10 Ago 2006 & Concreting of the V2N-P3P4 span \\
4 & 13 Ago 2006 & Prestressing of the V2N-P3P4 span \\
\hline
\end{tabular}

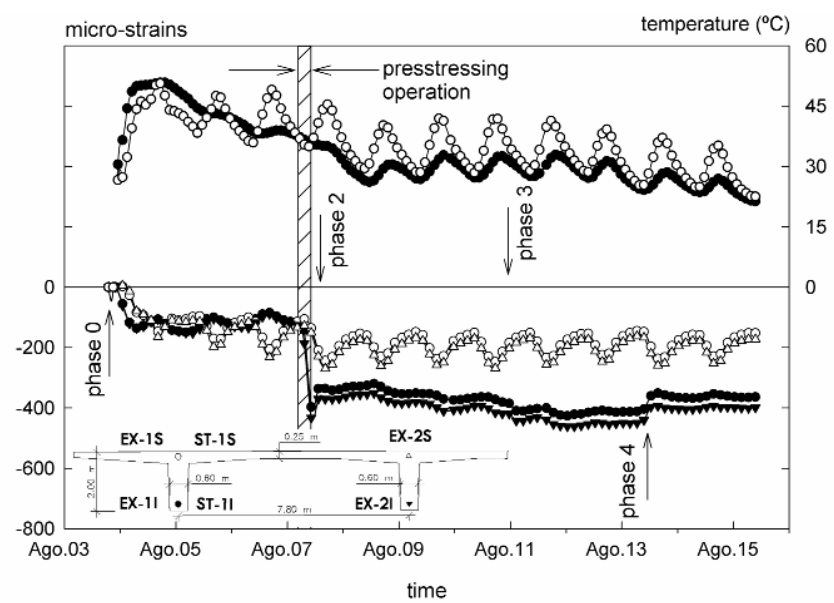

Figure 7. Structural and thermal observations of the P2P3 section during the span construction.

In what it concerns to the temperature evolution a distinguished path is observed in the top and bottom layer of the instrumented section $\mathrm{P} 2 \mathrm{P} 3$. The concrete temperature in the top layer of the deck achieves to equilibrium with environmental temperature more quickly. This fact is explained by the framework that bounds the bottom face of the viaduct deck during its construction until the phase 1 finish. Even so, after the phase 2 the observed temperature range is greater in the upper face due to the direct incidence of the sun, contrarily to what happens in the lower face that is always to the shade.

The time dependent effects in the concrete is also perceptible by a smooth measure variation along the time, namely at the bottom layer where the prestress- 
ing effect was considerable greater leading to a more strong creep evolution. Based in the strain measurements and the effective concrete properties (TACE 2007), the concrete stress evolution can be estimated by Equation 3. Figure 8 illustrates the concrete stress evolution in the middle section $\mathrm{P} 2 \mathrm{P} 3$ during the span prestressing. The minimum compressive stress registered in concrete is lower than $0.4 \mathrm{f}_{\mathrm{c}, 3.5 \mathrm{~d}}$, guaranteeing therefore the elastic domain of the concrete.

$\Delta \sigma_{c}=\Delta \varepsilon_{c} \cdot E_{c}\left(t_{\text {phase } 1}\right)$

With the estimated values for the concrete stress, the axial and bending efforts can be estimated by the Equations 4 and 5 respectively.

$\Delta \sigma_{c}=\frac{P}{A}+\frac{P \cdot e}{I} \cdot d \Rightarrow P=\frac{\Delta \sigma_{c} \cdot A \cdot I}{(I+e \cdot A) \cdot d}$

$M=P \cdot e$

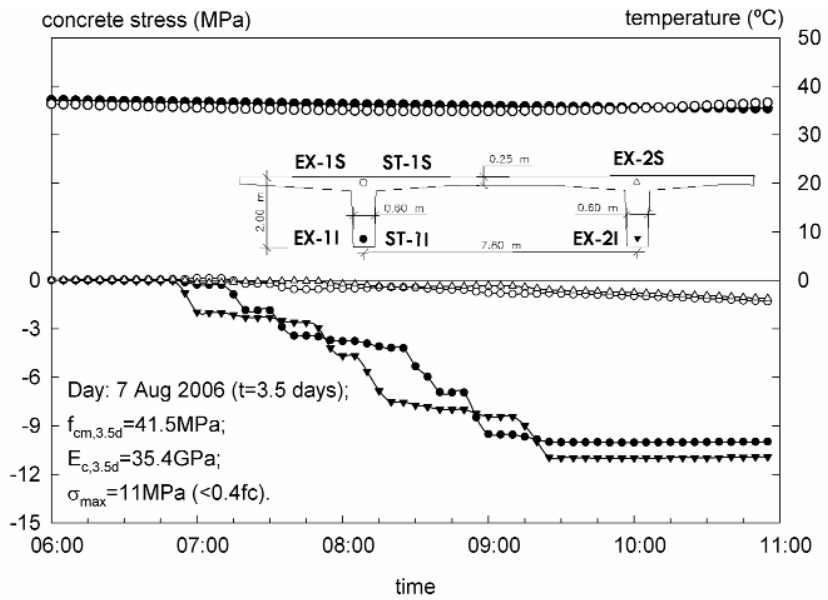

Figure 8. Concrete stress evolution in section $\mathrm{P} 2 \mathrm{P} 3$ during the span $\mathrm{P} 2 \mathrm{P} 3$ prestressing.

Taking the stress average for the bottom layer, the axial force produced by the prestressing operation was estimated in $9423 \mathrm{KN}$ and the respective bending moment due the eccentricity in $-12426 \mathrm{kNm}$.

\subsection{Long-term monitoring - The bearings behavior}

In bridges, the bearings repair and/or substitution has a high cost for the owner, and by this reason is more than justified to monitor its behavior in a long-term manner. In the Lezíria Bridge a set of bearings displacements are observed with LVDT's, namely the bearings on two north viaducts (V2N and $\mathrm{V} 3 \mathrm{~N}$ ), main bridge, and four south viaducts (V1S, V2S, V13S and V14S). From all of them, a singular behavior has been observed in the bearings between pillar P7 and the bridge deck. Figure 9 illustrates this zone of the main bridge, were the deck is supported by pillars P7 and PTS1 with bearings. It is also illustrated the instrumentation setup with indication of the relevant measurement points for this case, namely two bearings displacements (one in pillar P7 and the other in the south extreme of the main bridge, PTS1) and concrete strains in the top of the pillar P7 as well as the concrete temperature.

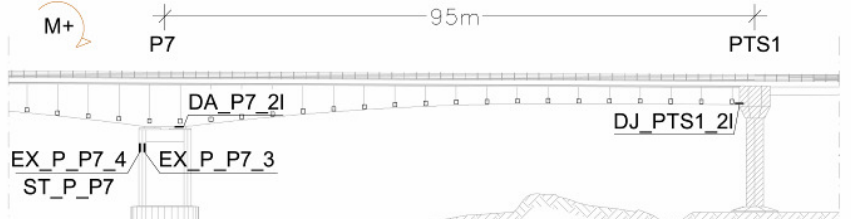

Figure 9. Sensors location in pillar P7 and PTS1 in the main bridge.

Figure 10 presents a time window observation of six days with the evolution of the displacements in the bearings P7 and PTS1, as well as the temperature measured in the pillar concrete.

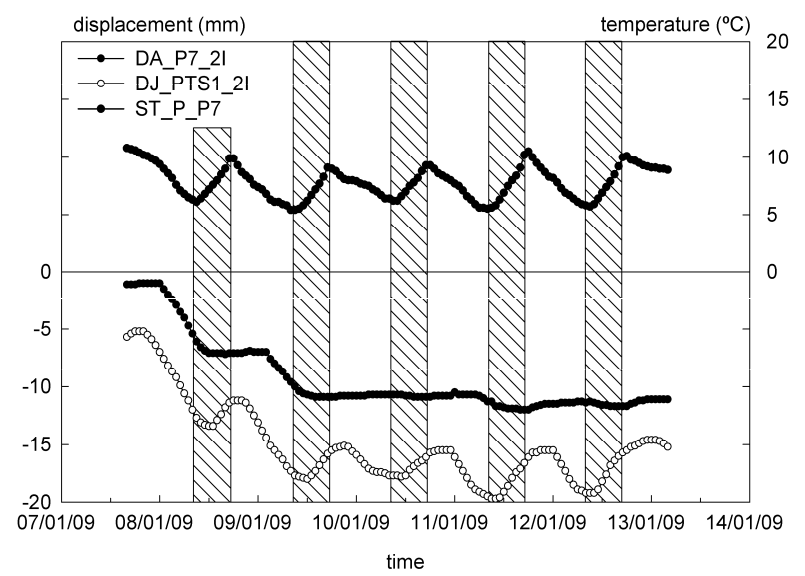

Figure 10. Measured displacements in bearings P7 and PTS1.

While the bearing displacement in PTS1 presents a good correlation with measured temperature (both signals are in phase), the bearing displacement in P7 has low correlation with the same temperature with visible step bands (null displacement for temperature variation). This can indicate friction in the bearing P7. If this friction reach to a certain magnitude can produce a bending behavior of the pillar P7.To verify this possibility, Figure 11 presents the strains evolution measured in the top of the pillar P7 for the same window time presented in Figure 10.

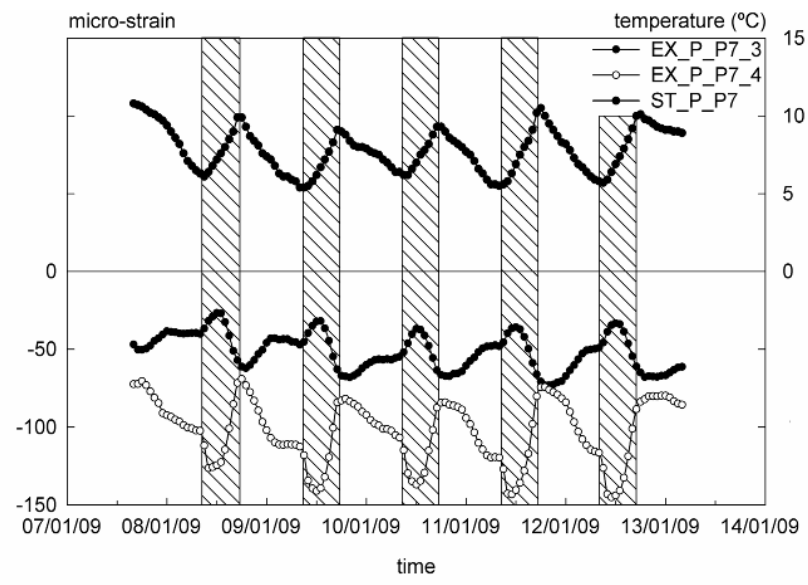

Figure 11. Measured strains in the top of pillar P7. 
The measured strains present a good correlation with the temperature, except in the time bands where the concrete temperature increases (hatched area). Fast signal variation is observed in the strain gauges near the extreme zone of the hatched areas. Crossing the information from Figures 10 and 11, it is suggested the existence of friction in bearing P7 when the concrete temperature goes from the daily minimum to the daily maximum, because a bending behavior not correlated with the temperature variation is observed in the top section of pillar P7 during this period. Further studies must be made to investigate this singular behavior.

\subsection{Short-term monitoring - Traffic events}

To complement the long-term observation of time dependent effects, sensors like accelerometers and optical strain gauges have the capability of measure short-term events. Those short-term events can be seismic actions, boats colliding with the columns, and traffic events such as heavy vehicles passaging over the bridge or even the passing of the train underneath the north viaduct V2N.

Based in a developed algorithm, "mensus_traffic" (Sousa et al. 2010), it is possible to extract information related with the passage of heavy vehicles like weight, velocity and traffic stream, from time series with high sampling rate. A case study is presented related to a continuous observation period of $24 \mathrm{~h}$ with a sampling rate of $50 \mathrm{~Hz}$. Two optical strain gauges are considered and are located in two cross sections distant of $130 \mathrm{~m}$, sections S-A and S-B, at the mid span between the pillars P1, P2 and P2, P3 respectively. In those two sections, the strain gauges are positioned at the bottom layer of the cross section of the box girder, "S-A_SG_Inferior" and "SB_SG_Inferior" respectively. Figure 12 help in the comprehension of the previously description.

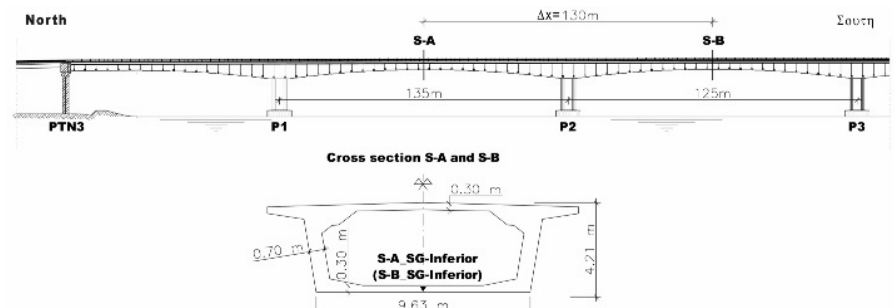

Figure 12. Strain-gauges location used for "mensus_traffic".

From the referred observation period, Figure 13 shows a time window of $4 \mathrm{~m} 40 \mathrm{~s}$ with data collected from strain gauges "S-A_SG_Inf" and "SB_SG_Inf". The local extremes detected by the algorithm "mensus_trafiic" are indicated also (small circles). The identified local extreme values correspond to traffic events associated with the passage of heavy vehicles in those sections. The time delay between the values of each pair is the time that the traffic event needs to reach to section S-B (or S-A) and comes from the section S-A (or S-B).

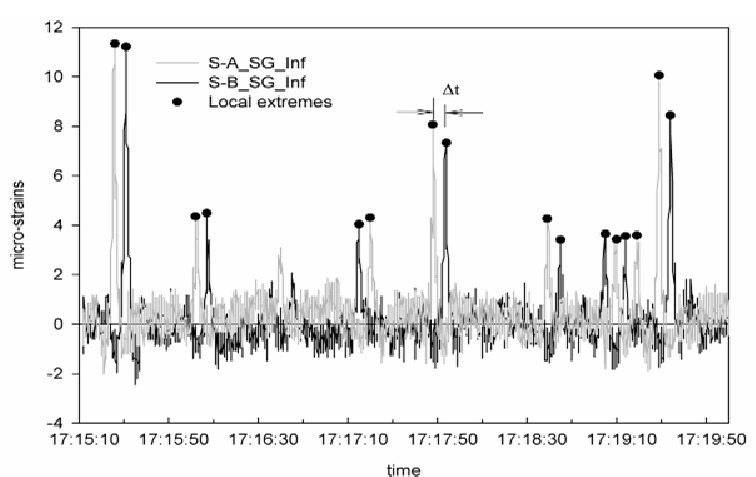

Figure 13. Local extremes identification from strain gauges data "S-A_SG_Inf" "S-B_SG_Inf".

Based in the load tests performed during the bridge construction, a relation of $9.35 \mathrm{ton} / \mu \varepsilon$ was established for the bottom layer deformation of the box girder at mid span between pillars P1 and P2 (section S-A). With this information the identified local extremes can be correlated with the expected event traffic weight. Due to the noise amplitude, the minimum value considered for local extremes detection was set to $3 \mu \varepsilon$. This restricts the possibility of detecting traffic events only above 28 ton. In these conditions, during the observation period a total of 581 traffic events with weight above 28ton were detected, and from those $3 \%$ surpass the 100ton corresponding perhaps to special transportations. Figure 14 illustrates the number of occurrences for different weight classes in a manner of weight spectrum.

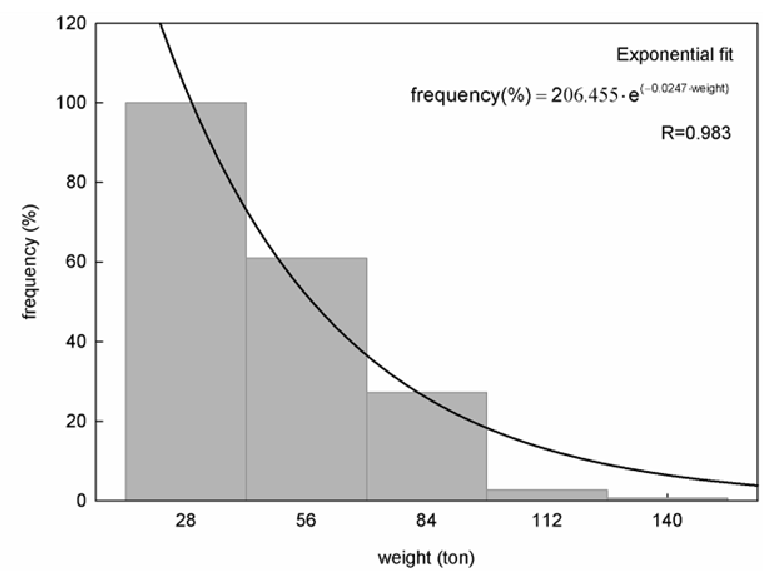

Figure 14. Traffic events weight spectrum.

Considering the local extremes pairs, it is also possible to estimate the velocity of the traffic events that originate those local extremes, resorting to Equation 6. The value of $\Delta \mathrm{x}$ is the distance between section $\mathrm{S}-\mathrm{A}$ and $\mathrm{S}-\mathrm{B}$ (Figure 12), and the $\Delta \mathrm{t}$ value is the time delay between the two local extremes of each pair (Figure 13). Figure 15 presents the velocity histogram as well as the normal distribution fitting based in the formulation expressed in Equation 6 and the pairs of local extreme identified. The average speed from that distribution is about $89 \mathrm{~km} / \mathrm{h}$, which conforms with the speed limit established for the heavy traffic in Portugal, whose value is $90 \mathrm{~km} / \mathrm{h}$. 


$$
v=\frac{\Delta x}{\Delta t}=\frac{\Delta x}{t_{2}-t_{1}}
$$

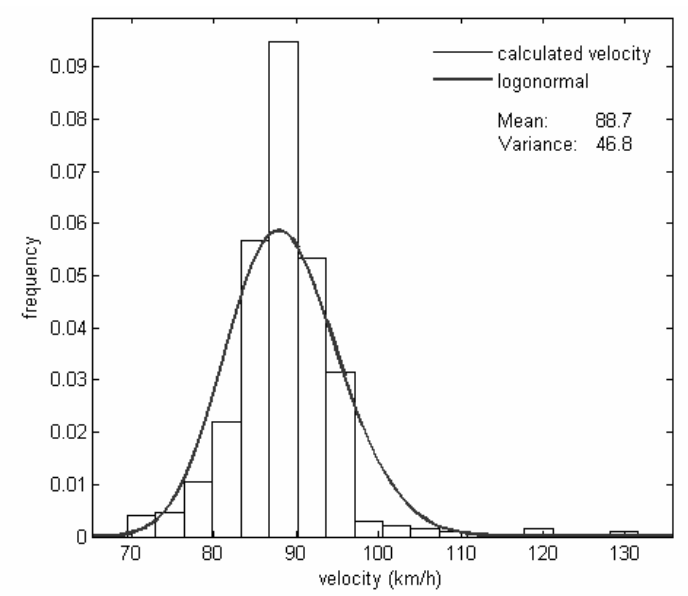

Figure 15. Traffic events velocities distribution.

\section{CONCLUSIONS}

The cases here presented related with the Lezíria Bridge monitoring demonstrate how the collected data can be useful for the assessment and surveillance of the structure, namely by: (i) characterization of the environmental conditions with relevance for an accurate evaluation of the time dependent effects of concrete as well as the structure expansion and contraction along the time; (ii) structure safety during the construction with control of stress levels on concrete in important construction events; (iii) detection of non expected behavior by cross information obtained by the sensors in a long-term analysis; (iv) make use of the monitoring system to characterize short-term events like traffic, where it can be extracted information about the real live loads that the bridge is submitted.

The gathering of all this information is a first step for the data treatment and processing with the objective of creating automatic procedures for the assessment and surveillance of the structure.

\section{ACKNOWLEDGEMENTS}

As usual for in-situ works, there are many relevant if not decisive personal contributions. It would be impossible and displaced to mention them exhaustively here. Nevertheless, the authors wish to thank to all those who contributed to the success of the implementation of this system, including the LABEST team, the NewMENSUS, the contractor TACE, and the bridge owner, BRISA SA. The first author also expresses thankfulness to the Portuguese Foundation for Science and Technology for the funding of his doctoral studies.

\section{REFERENCES}

Arenas, J., Ortega, A. (1998). "Puente Las Oblatas en Pamplona." Hormigón Y Acero, $4^{\circ}$ Trimestre, 41-53. (in Spanish)

Beeby, A. W. 2005. Designers' guide to EN 1992-1-1 and EN 1992-1-2 :Eurocode 2: design of concrete structures : general rules and rules for buildings and structural fire design. London: Thomas Telford. (Designers' guides to the Eurocodes).

Barcina, J., Mato, F. (1997). "IV Puente sobre el río Guadiana, en Badajoz. Instrumentación y control del atiramento." Hormigón Y Acero, $4^{\circ}$ Trimestre, 63-79. (in Spanish)

Buonomo, M., et al. (2004). "The Design and Construction of the Millau Viaduct." Steelbridge 2004, Millau, 23-25 June 2004.

Curran, P., Tilly, G. (1999). "Design and Monitoring of the Flintshire Bridge, UK." Structural Engineering International, 9(3), 225-228.

Ducret, J., Lebet, J. (1999). "Behaviour of Composite Bridges during Construction" Structural Engineering International, 9(3), 49-52.

Figueiras, J. et al. 2007. Construção da Travessia do Tejo no Carregado Sublanço A1/Benavente, da A10 Auto-Estrada Bucelas/Carregado/IC3: Projecto Executivo Monitorização Estrutural e de Durabilidade 0 - Apresentação. LABEST, Faculdade de Engenharia da Universidade do Porto. (in Portuguese)

Froli, M., et al. (1996). "Longitudinal Thermal Behaviour of a Concrete Box Girder Bridge" Structural Engineering International, 6(4), 49-52.

García, F., Carrera, G. (1998). "Puente sobre el Río Guadalete de tablero de vigas pretensazas prefabricadas de Hormigón de Alta Resistencia." Hormigón Y Acero, $1^{\circ}$ Trimestre, 6781. (in Spanish)

Jordet, E., Jakobsen, S. (2007). "The Svinesund Bridge, Norway/Sweden" Structural Engineering International, 17(4), 309-313.

Karoumi, R. (consulted in 2009). "Monitoring of the new Svinesund Bridge." Internet address: http://www.byv.kth.se/svinesund/index.htm.

Luengo, J., et al. (2000). "El puente sobre el río Ebro en RibaRoja." Hormigón Y Acero, $2^{\circ}$ Trimestre, 17-25. (in Spanish)

Oliveira, C. B. 2006. "New crossing of the Tagus river from Carregado to Lezíria through A10." Ingenium, $n^{\circ}$ 95. (in Portuguese)

Ridruego, G. (2006). “Almonte Arch La Plata dual Carriageway. Hinojal-Cáceres stretch." Hormigón Y Acero, $2^{\circ}$ Trimestre, 5-28.

Sousa, H., et al. 2008. MENSUSMONITOR - Tool for the treatment and interpretation of experimental results in Civil Engineering. CCC 2008 - Challenges for Civil Construction. Porto: FEUP.

Sousa, H., et al. 2010. MENSUSMONITOR - Algorithm implementation for detecting live load events and assessment of structural effects on bridges. IABMAS2010 - The Fifth International Conference on Bridge Maintenance, Safety and Management. Philadelphia, Pennsylvania, USA.

TACE 2007. Construção da Travessia do Tejo no Carregado Sublanço A1/Benavente, da A10 Auto-Estrada Bucelas/Carregado/IC3: Plano de Qualidade. (in Portuguese)

Tang, M., et al. (2002). "Construction of the My Thuan CableStayed Bridge" Concrete International, 24(2), 49-52.

Tomita, M., et al. (1999). "Shin-Karato Bridge in Kobe, Japan" Structural Engineering International, 9(2), 109-110. 